\title{
DEMOGRAPHIC AND SOCIO-ECONOMIC FACTORS AFFECTING BIRTH PREPARATION AND COMPLICATION READINESS (BPCR) PRACTICES IN NEPAL
}

\begin{abstract}
Sunil Kumar Acharya*
BPCR practices by women in Nepal are still low. Still a relatively high percentage of women do not make BPCR to its fullest extent. Researches in developing countries show that various demographic, social and economic factors influence the BPCR practices by pregnant women. This paper examines the likelihood of BPCR practices based on women's demographic, social and economic status in Nepal. NDHS 2011 data set has been utilized by applying bivariate logistics regression analysis technique to examine the effects of these variables on BPCR practices in Nepal. The analysis result shows high variations and gaps in BPCR practice based on demographic, social and economic status of women. Against this finding the study recommends implementation of appropriate policy and program measures by the government and other agencies to address the existing variations and gaps in BPCR practices among subgroups of women in Nepal. Further research studies focusing on the existing barriers on BPCR practice need to be conducted in Nepal especially among the women who are disadvantaged and marginalized.
\end{abstract}

Keywords: Birth preparedness, complication readiness, clean delivery kits and antenatal care.

\section{INTRODUCTION}

Women and newborns need timely access to skilled care during pregnancy, childbirth, and the postpartum/newborn period. Too often, however, their access to care is impeded by delays: delays in deciding to seek care, delays in reaching care, and delays in receiving care. Delays in deciding to seek caremay be caused by failure to recognize signs of complications, failure to perceive the severity of illness, cost considerations, previous negative experiences with the healthcare system, and transportation difficulties. Delays in reaching caremay be created by the distance from a woman's home to a facility or provider, the condition of roads, and a lack of emergency transportation. Delays in receivingcaremay result from unprofessional attitudes of providers, shortages of supplies and basic equipment, a lack of healthcare personnel, and poor skills of healthcare providers (Jhpiego, 2004). Thus Birth Preparedness and Complication Readiness (BPCR)is the process of planning for normal birth and anticipating the actions needed in case of an emergency.Because life-threatening complications can occur during the early postpartum period, birth preparedness also includes preparing/planning for accessing postpartum care during the first week after delivery and at six weeks after delivery (FCI, 2007).

Key elements of birth preparedness include: attending antenatal care at least four times during pregnancy; identifying a skilled provider and making a plan for reaching the facility during labour; setting aside personal funds to cover the costs of travelling to and delivering with a skilled provider and any required supplies; recognizing signs of complications; knowing what community

* Dr. Acharya is Lecturer at Central Department of Population Studies (CDPS), Tribhuvan University, Kirtipur, Kathmandu, Nepal. 
resources for emergency transport, funds, communications, etc. are available in case of emergencies; having a plan for emergencies i.e. knowing what transport can be used to get to the hospital, setting aside funds; identifying person(s) to accompany to the hospital and/or to stay at home with family; and identifying a blood donor.

Research conducted in Nepal and other countries have exhibited strong linkages between demographic and socio-economic variables of women and their practices on BPCR (Tura, Afework,\& Yalew, 2014; Kaphle, Neupane, Kunwar, \& Acharya, 2015; Ekabua, Kufre, Odusolu, Agan, Iklaki, \& Etokidem, 2011; Kaso \& Addise, 2014; Markos \& Bogale, 2014; and Karkee, Lee,\& Binns, 2013). These research studies have exhibited the effects of several demographic, social and economic factors in whether a women practice BPCR once they are pregnant.The following sections therefore present the likelihood effect of these variables on BPCR practices in Nepal.

\section{METHODS}

Data files of Nepal Demographic and Health Survey 2011 have been utilized to analyze the effects of demographic, social and economic factors on the utilization of safe motherhood services in Nepal. The total sample of the survey consists of 4,079 currently married women between the ages of 15-49 years who had given birth to a child in the 5 years preceding the survey date. After applying weightage the sample size is derived at 4,148 women.

Following 5 components of birth preparedness have been included in data analysis: saving of money, arrangement of transport, arrangement of blood or a blood donor, identification of a skilled health worker or health institution for delivery, and arrangement of clean delivery kit. Arrangement of food and clothes and other preparations have been excluded in the analysis. These 5 components of BPCR are internationallyrecommended precautions to be taken by pregnant women and families.

The paper has defined two sets of variables which are respectively categorized as dependent and independent. BPCR practice is taken as dependent variable. Independent variables include demographic (woman's current age, age at $1^{\text {st }}$ birth, children ever born, number of children $<5$ years of age, pregnancy termination/induced abortion), social (caste/ethnicity, religion, woman's education, husband's education, mass media habits, spatial distribution, and rural/urban residence)and economic(woman's occupation, husband's occupation, woman's employment status, household wealth) concerning the woman and her family members. These variables influence the safe motherhood behaviour and practices of an individual woman.

The dependent and independent variables have been re-categorized from the data file to make a meaningful analysis. Data has been analyzed by using STATA Version 12. First, data is analyzed on the basis of cross tabulations of dependent and independent variables. Second, bivariate logistic regression has been used to predict the likelihood of BPCR practices by pregnant women in Nepal.

\section{RESULTS}

\section{Demographic variables and birth preparedness practices}


Comparatively birth preparedness by pregnant women is low in Nepal. In 2003 more than one in three women (37\%) saved money for delivery, 9 percent bought a home delivery kit, 4 percent contacted a health worker, and about 26 percent arranged for food and clothing for the newborn. Nearly one in two mothers reported of no birth preparations in the last pregnancy. Men's responses differed somewhat from women's responses. Fifty-four percent of men mentioned that they saved money for the birth, 10 percent of men said they bought a home delivery kit, 9 percent contacted a health worker, and 6 percent arranged for transport. About 29 percent of men said they did not make any preparations for the birth of their youngest child (MoHP, 2007).

In 2011 more than 1 in 3 (36\%) saved money for delivery. Five percent bought a home delivery kit and 2 percent contacted a health worker. These figures are lower in comparison to similar data in the 2006 NDHS. More than half of women (56\%) arranged for food and clothing for the newborn in 2011, in comparison to 26 percent in 2006. Arrangements of transportation however slightly increased from 1 percent in 2006 to 3 percent in 2011. More than one-third (35.4\%) of women said they had not made any preparations at all for the birth of their last child (MoHP, 2012).

Overall, the data analysis result showed that nearly 4 in every 10 women (39.1\%) reported of making at least 1 component of birth preparations in their last pregnancy. By current age about 40 percent of women each in the age groups of 15-19, 20-24 and 25-29 years had made birth preparations in their last pregnancy. Likewise, BPCR practice was highest among women whose age at first birth was 20-24 (42.9\%) and 25-29 (48.9\%) years. By parity, BPCR practice was high (47.2\%-45.8\%) among women who had 1 or 2 child. Birth preparation among women who ever had pregnancy termination (induced abortion) was also found slightly high. By 4 or more ANC use, over half of the women (54.1\%) who had utilized ANC services 4 or more times had also made birth preparations. Comparatively only 24 percent of women who had not utilized ANC services 4 or more times had made birth preparations for delivery of last pregnancy (Table 1).

Table 1: Effects of selected demographic variables on BPCR practices in Nepal using logistic regression

\begin{tabular}{|l|r|r|r|c|c|}
\hline \multirow{2}{*}{ Background variables } & \multicolumn{2}{|c|}{ Respondents } & \multicolumn{3}{|c|}{ Logistic regression results } \\
\cline { 2 - 6 } & Total & $\begin{array}{c}\text { \% Utilizing } \\
\text { BPCR }\end{array}$ & $\begin{array}{c}\text { Odds ratio } \\
\text { (OR) }\end{array}$ & $\begin{array}{c}\text { Confidence } \\
\text { interval (CI) }\end{array}$ & P value \\
\hline Age group & 333 & 43.2 & Ref. & & \\
$15-19$ & 1,328 & 41.7 & 0.937 & $0.692-1.269$ & 0.674 \\
$20-24$ & 1,310 & 42.7 & 0.977 & $0.722-1.321$ & 0.878 \\
$25-29$ & 670 & 35.7 & 0.727 & $0.522-1.013$ & 0.060 \\
$30-34$ & 316 & 27.8 & 0.506 & $0.339-0.754$ & 0.001 \\
$35-39$ & 140 & 21.4 & 0.359 & $0.201-0.642$ & 0.001 \\
$40-44$ & 50 & 12.0 & 0.164 & $0.055-0.492$ & 0.001 \\
$45-49$ & & & & & \\
Age at first birth & 66 & 28.8 & 0.673 & $0.248-1.829$ & 0.438 \\
$10-14$ & 2,126 & 35.4 & 0.938 & $0.457-1.925$ & 0.861 \\
$15-19$ & 1,645 & 42.9 & 1.284 & $0.624-2.641$ & 0.497 \\
$20-24$ & 264 & 48.9 & 1.625 & $0.753-3.506$ & 0.216 \\
$25-29$ & 264 & 48.9 & Ref. & & \\
$30+$ & & & & & \\
\hline
\end{tabular}


.. Table 1 continued

\begin{tabular}{|c|c|c|c|c|c|}
\hline \multirow[b]{2}{*}{ Background variables } & \multicolumn{2}{|c|}{ Respondents } & \multicolumn{3}{|c|}{ Logistic regression results } \\
\hline & Total & $\begin{array}{l}\text { \% Utilizing } \\
\text { BPCR }\end{array}$ & $\begin{array}{l}\text { Odds ratio } \\
\text { (OR) }\end{array}$ & $\begin{array}{l}\text { Confidence } \\
\text { interval (CI) }\end{array}$ & $\mathrm{P}$ value \\
\hline \multicolumn{6}{|l|}{ Children ever born } \\
\hline 1 & 1,302 & 47.2 & 3.651 & $2.736-4.872$ & 0.000 \\
\hline 2 & 1,162 & 45.8 & 3.445 & $2.574-4.610$ & 0.000 \\
\hline 3 & 733 & 37.2 & 2.424 & $1.769-3.322$ & 0.000 \\
\hline 4 & 397 & 23.4 & 1.240 & $0.861-1.785$ & 0.249 \\
\hline $5+$ & 555 & 19.5 & Ref. & & \\
\hline \multicolumn{6}{|l|}{ Child $<5$ years } \\
\hline None & 247 & 41.7 & 1.259 & $0.674-2.354$ & 0.470 \\
\hline 1 & 2,181 & 43.3 & 1.345 & $0.776-2.331$ & 0.291 \\
\hline 2 & 1,335 & 34.5 & 0.931 & $0.533-1.626$ & 0.802 \\
\hline 3 & 299 & 27.8 & 0.675 & $0.361-1.261$ & 0.218 \\
\hline $4+$ & 86 & 34.7 & Ref. & & \\
\hline \multicolumn{6}{|l|}{ Pregnancy termination } \\
\hline Yes & 796 & 40.2 & 1.058 & $0.878-1.273$ & 0.554 \\
\hline No & 3,352 & 38.8 & Ref. & & \\
\hline \multicolumn{6}{|l|}{$\begin{array}{l}\text { Utilization of ANC } 4 \text { or } \\
\text { more }\end{array}$} \\
\hline Yes & 2,078 & 54.1 & 3.729 & $3.265-4.257$ & 0.000 \\
\hline No & 2,071 & 24.0 & Ref. & & \\
\hline Total & 4,149 & 39.1 & & & \\
\hline
\end{tabular}

Weights are applied and totals may not equal 100.0 due to rounding off of cases.

Source: Calculated from NDHS 2011 data files.

The logistic regression analysis on the effects of selected demographic variables on the likelihood of birth preparation practices among Nepalese women shows that women's age does not have strong positive effect on BPCR practices. But women who have one CEB are 3.65 times more likely (95\% CI=2.736-4.872; $\mathrm{p}<0.005)$ and women with 2 CEB are 3.44 times more likely $(95 \%$ $\mathrm{CI}=2.574-4.610$ ) to practice BPCR. Similarly, women with 3 CEB are 2.42 times more likely to practice birth preparations. Utilization of ANC services has strong effects on BPCR in Nepal since the women who have utilized ANC services 4 or more times are strongly likely $(\mathrm{OR}=3.729$; $\mathrm{CI}=3.265-4.257$; $\mathrm{p}<0.005$ ) to make birth preparations than the women who did not take ANC services or took the services less than 4 times. The other demographic variables do not show any effect on BPCR practices in Nepal (Table 1).

\section{Social variables and BPCR practices}

According to caste or ethnicity, the data analysis result shows that the BPCR practice was high among Newar (48.8\%) and Brahmin/Chhetri (46.8\%) caste/ethnic groups. Similarly, BPCR practice was also relatively high among Hill and Terai Janajati (38.3\%) and Dalit (36.2\%) ethnic groups. The lowest BPCRpractice was among other Terai ethnic (24.2\%) groups. By religion, the BPCR practice among Hindu and non-Hindu religious groups of women was found nearly the same (39.6\% - 36.8\%). Similarly, over one-half (56\%) of women in urban areas had practiced BPCR in their last pregnancy while only about 37 percent women in rural areas had practiced 
BPCR. By ecological regions the practice was highest in Terai (41.5\%) followed by Hills (37.4\%) and the lowest was in Mountains (30.4\%) (Table 2).

Table 2: Effects of selected social variables on BPCR practices in Nepal using logistic regression

\begin{tabular}{|c|c|c|c|c|c|}
\hline \multirow[b]{2}{*}{ Background variables } & \multicolumn{2}{|c|}{ Respondents } & \multicolumn{3}{|c|}{ Logistic regression } \\
\hline & Total & $\begin{array}{l}\text { \% Utilizing } \\
\text { BPCR }\end{array}$ & $\begin{array}{l}\text { Odds ratio } \\
\text { (OR) }\end{array}$ & $\begin{array}{l}\text { Confidence } \\
\text { interval (CI) }\end{array}$ & $P$ value \\
\hline \multicolumn{6}{|l|}{ Caste/ethnicity } \\
\hline Brahmin/Chhetri \& other castes*+ & 1,283 & 46.8 & 2.070 & $1.352-3.169$ & 0.001 \\
\hline Other Terai Caste & 414 & 24.2 & 0.748 & $0.449-1.246$ & 0.265 \\
\hline Dalit & 683 & 36.2 & 1.333 & $0.848-2.0949$ & 0.213 \\
\hline Newar & 127 & 48.8 & 2.244 & $1.255-4.012$ & 0.006 \\
\hline Hill and Terai Janajati & 1,396 & 38.3 & 1.454 & $0.946-2.234$ & 0.087 \\
\hline Muslim & 235 & 29.8 & Ref. & & \\
\hline \multicolumn{6}{|l|}{ Religion } \\
\hline Hindu & 3,444 & 39.6 & 1.128 & $0.912-1.395$ & 0.267 \\
\hline Others & 704 & 36.8 & Ref, & & \\
\hline \multicolumn{6}{|l|}{ Residence } \\
\hline Rural & 3,730 & 37.2 & Ref. & & \\
\hline Urban & 418 & 56.0 & 2.140 & $1.792-2.556$ & 0.000 \\
\hline \multicolumn{6}{|l|}{ Ecological region } \\
\hline Mountain & 305 & 30.8 & 0.628 & $0.517-0.763$ & 0.000 \\
\hline Hill & 1,669 & 37.4 & 0.842 & & 0.033 \\
\hline Terai & 2,174 & 41.5 & Ref. & Ref. & \\
\hline \multicolumn{6}{|l|}{ Respondent education } \\
\hline Higher & 263 & 67.7 & 0.167 & $0.119-0.233$ & 0.000 \\
\hline Secondary & 1,230 & 51.8 & 0.318 & $0.224-0.451$ & 0.000 \\
\hline Primary & 834 & 40.0 & 0.510 & $0.365-0.715$ & 0.000 \\
\hline No education & 1,822 & 26.0 & Ref. & & \\
\hline \multicolumn{6}{|l|}{ Husband education** } \\
\hline Higher & 461 & 60.3 & 0.194 & $0.143-0.263$ & 0.000 \\
\hline Secondary & 1,809 & 46.3 & 0.287 & $0.218-0.377$ & 0.000 \\
\hline Primary & 984 & 30.4 & 0.566 & $0.442-0.725$ & 0.000 \\
\hline No education & 872 & 22.8 & Ref. & & \\
\hline \multicolumn{6}{|l|}{ Media habits } \\
\hline \multicolumn{6}{|l|}{ Newspaper } \\
\hline At least once a week & 299 & 65.2 & 0.257 & $0.191-0.346$ & 0.000 \\
\hline Less than once a week & 777 & 55.3 & 0.663 & $0.477-0.921$ & 0.014 \\
\hline Not at all & 3,071 & 32.4 & Ref. & & \\
\hline \multicolumn{6}{|l|}{ Radio } \\
\hline At least once a week & 1,535 & 46.6 & 0.498 & $0.404-0.615$ & 0.000 \\
\hline Less than once a week & 1,617 & 37.4 & 0.686 & $0.579-0.812$ & 0.000 \\
\hline Not at all & 996 & 30.3 & Ref. & & \\
\hline
\end{tabular}


Table 2 continued

\begin{tabular}{|l|r|r|r|r|r|}
\hline \multirow{2}{*}{ Background variables } & \multicolumn{2}{|c|}{ Respondents } & \multicolumn{2}{|c|}{ Logistic regression } \\
\cline { 2 - 6 } & Total & $\begin{array}{c}\text { \% Utilizing } \\
\text { BPCR }\end{array}$ & $\begin{array}{c}\text { Odds ratio } \\
\text { (OR) }\end{array}$ & $\begin{array}{c}\text { Confidence } \\
\text { interval (CI) }\end{array}$ & P value \\
\hline Television & 1,561 & 52.6 & 0.278 & $0.230-0.338$ & 0.000 \\
At least once a week & 1,144 & 40.2 & 0.607 & $0.504-0.732$ & 0.000 \\
Less than once a week & 1,442 & 23.6 & Ref. & & \\
Not at all & 162 & 63.0 & 2.781 & $1.866-4.144$ & 0.000 \\
Mass media habits & 3,987 & 38.1 & Ref. & & \\
Yes & 4,149 & 39.1 & & & \\
No & & & & & \\
\hline Total & & & & & \\
\hline
\end{tabular}

*11 cases missing. **22 cases missing.

+Caste/ethnicity has been re-grouped.

Weights are applied and totals may not equal 100.0 due to rounding off of cases.

Source: Calculated from NDHS 2011 data files.

High percentage of women with higher level of education had made BPCR in their last pregnancy than those who had low or no education. For example, about 67 percent with high level of educational attainment (higher secondary or above) and about 52 percent of women with secondary level of education had made birth preparations. It is also noted that BPCR use was highest (60\%) among women whose husband had attended higher level of education. By media habits, overall BPCR practice was found high among women (63\%) who had habits of using media channels such as newspaper, radio, and TV (Table 2).

The logistic regression analysis results shows a strong likelihood of BPCRamong Brahmin/Chhetri $(\mathrm{OR}=2.070 ; 95 \% \mathrm{CI}=1.352-3.169 ; \mathrm{p}<0.001)$ and Newar $(\mathrm{OR}=2.244 ; 95 \% \mathrm{CI}=0.946-2.234)$ caste/ethnic groups of women. Similarly Women residing in urban areas are 2.14 times more likely to practice BPCR than those living in rural areas. Women who use different media channels like newspaper, radio and TV are more likely to practice BPCR. Overall, women who have the habits of using the above three media channels are 2.7 times more likely (95\% CI=1.866-4.144; $\mathrm{p}<0.001$ ) to practice BPCR than those who do not have the habits of using these media channels. Women's and their husband's education also has some effect as women or their husband with some education are more likely to practice BPCR than the women or their husband who have no education. The logistic regression analysis does not show much effect of other social variables like religion and ecological region (Table 2).

\section{Economic variables and BPCRpractices}

Table 3 presents data on BPCR practices among women based on their economic characteristics. The result shows that the practice of BPCR was highest among women whose occupation was service/trade (55.3\%) and those in manual labour (48.4\%). BPCR among women who were not working was also relatively high (43.4\%). The lowest percentages of women reporting of making 
BP were from agriculture (33.7\%) sector. It is also noted that BPCR practice was highest among women whose husband's occupation was service/trade (48.5\%) followed by those involved in manual labour (37.2\%). By employment status BPCR practice was high among women who were not currently employed (41.9\%). By household wealth status BPCR practice was highest among women who belonged to rich (53.4\%) followed by those in middle (38.6\%) wealth quintiles (Table 3).

Table 3: Effects of selected social variables on BPCR practices in Nepal using logistic regression

\begin{tabular}{|l|r|r|r|r|r|}
\hline \multirow{2}{*}{ Background variables } & \multicolumn{2}{|c|}{ Respondents } & \multicolumn{3}{|c|}{ Logistic regression } \\
\cline { 2 - 6 } & Total & $\begin{array}{c}\text { \% Utilizing } \\
\text { BPCR }\end{array}$ & $\begin{array}{c}\text { Odds ratio } \\
\text { (OR) }\end{array}$ & $\begin{array}{c}\text { Confidence } \\
\text { interval (CI) }\end{array}$ & P value \\
\hline Respondent's occupation+ & 182 & 48.4 & 0.818 & $0.554-1.209$ & 0.314 \\
Manual & 398 & 55.3 & 0.542 & $0.373-0.786$ & 0.001 \\
Service/trade & 2,415 & 33.7 & 1.320 & $0.860-2.028$ & 0.204 \\
Agriculture & 1,150 & 43.4 & Ref. & \\
Not working & 1,315 & 37.2 & 0.648 & $0.523-0.804$ & 0.000 \\
Husband's occupation++ & 1,688 & 48.5 & 1.595 & $1.333-1.908$ & 0.000 \\
Manual & 1,006 & 27.7 & Ref. & \\
Service/trade & & & & & \\
Agriculture & 2,329 & 37.0 & 0.814 & $0.698-0.950$ & 0.009 \\
Respondent employment & 1,820 & 41.9 & Ref. & & \\
\hline Yes & 1,383 & 53.4 & 0.297 & $0.246-0.358$ & 0.000 \\
No & 1,383 & 38.6 & 0.550 & $0.454-0.665$ & 0.000 \\
Household wealth & 1,384 & 25.4 & Ref. & & \\
Rich & 4,150 & 39.1 & & & \\
Middle & & & & & \\
Poor & & & & \\
\hline Total & & & & \\
\hline
\end{tabular}

+2 missing cases, ++ 140 missing cases.

Weights are applied and totals may not equal 100.0 due to rounding off of cases.

Source: Calculated from NDHS 2011 data files.

The logistic regression result does not show some likelihood effects of economic variables on the practice of BPCR. Among the variables, women's occupation does not show a likelihood effect but some effect of BPCR practice is observed by husband's occupation. For example, women whose husband's occupation is service/trade are 1.59 times more likely (95\% CI=1.333-1.908; $\mathrm{p}<0.001)$ to practice BPCR than the women whose husband's occupation is manual or agriculture (Table 3).

Household wealth also does have some effect on BPCRpractice as women who belong to rich or middle wealth quintiles are more likely to practice BP than women in poor quintile (Table 3). 


\section{DISCUSSION}

This study has attempted to identify demographic and socio-economic factors that are associated with BPCR practices in Nepal. The overall finding showed only 39 percent women had made BPCR for the delivery of the last child. Data analysis result found that young age, age at $1^{\text {st }}$ birth, parity and number of young children ( $<5$ years) has strong effects on BPCR practices in Nepal. The logistic regression results does not show much effect by women's current age but other demographic factors such age at $1^{\text {st }}$ birth, parity and children's age somehow do have likely effect on BPCR practices. Strong effect was found among women who have had at least 4 ANC visits in their last pregnancy. The result was found significant at 5 percent level. Among others, this is indicative of the fact that utilization of ANC services (at least four times) may play important role in BPCR practice in Nepal. This result is consistent with other research studies conducted in Nepal and elsewhere which have also exhibited close association of demographic, social and economic factors with BPCR practices.A study conducted in Ethiopia found several socio demographic variables (women's education monthly income, parity and ANC visits were more likely to prepare for BPCR. The study also exhibited likelihood effect on BPCR practice of other variables like knowledge of danger signs of obstetric complications, presence of history of still birth, history of delivery at health facility before last delivery (Kaso\&Addise, 2014). Another study conducted in Ethiopia also confirms that maternal education, husband's occupation, wealth quintiles, birth interval, and knowledge of key danger signs during labour, and ANC visit were found to have statistically significant association with BPCR and skilled care use (Tura, Afework,\&Yalew, 2014).

In this study the data analysis result also shows some effect of social variables such as caste/ethnicity, place of residence (rural, urban) and education on BPCR practices.The finding on the effect of place of residence on BPCR practice is consistent with the finding of another study conducted in Ethiopia (Markos \&Bogale, 2014).The other social variables like level of women's education and access to media also have shown strong effects in Nepal which is confirmed by a study conducted in Pokhara by Kaphle et al. (2015). Strong effect of educational level on BPCR use was also foundin Ethiopia (Tura, Afework,\&Yalew, 2014).

The data analysis results in this study showed that the likelihood of BPCR practices in Nepal is strong among women who have access to all three medial channels than other women who have no or low access to these media channels. The analysis found strong likelihood effect of selected economic variables on BPCR practices. Overall, women who are employed and those belonging to rich and middle categories are more likely to practice BPCR than women whose occupation is agriculture, manual work or who are notworking. 


\section{CONCLUSION}

The data analysis showed variations and gaps in BPCR practices on the basis of demographic, social and economic characteristics of women such as women's age, parity and age at $1^{\text {st }}$ birth, caste/ethnicity and levels of education, employment status, household wealth and many others. Against this finding the paper recommends implementation of policy and program measures by the government and other agencies to address the existing variations and gaps in BPCR practices among women. As this study is solely based on quantitative data at national level it was not possible to carry out in-depth analysis of factors influencing BPCR use among sub-groups of population. Thus further in-depth research, both qualitative and quantitative, that address the demographic, economic and social diversity is recommended to be implemented which could help in understanding the knowledge, attitudes, and practices and identifythe barriers in BPCR practice in Nepal.

\section{REFERENCES}

Ekabua, J.E., Kufre, J.E., Odusolu, P., Agan, T. U., Iklaki, C. U., \& Etokidem, A. J. (2011). Awareness of birth preparedness and complication readiness in South-eastern Nigeria. ISRN Obstetrics and Gynecology, 2011. Retrieved From https://www.hindawi.com /journals/isrn/2011/560641/

FCI. (2007). Safe motherhood a review: 1987-2005. Review report. New York: FCI. Retrieved from http://www.familycareintl.org/UserFiles/File/SM\%20A \%20Review_ \%20Full_Report_FINAL.pdf.

Jhpiego. (2004). Monitoring birth preparedness and complication readiness, tools and indicators for maternal and newborn health. Policy andstrategy paper. New York: Johns Hopkins Bloomberg school of Public Health. Retrieved from http://pdf.usaid.gov/pdf_docs/pnada619.pdf.

Kaphle, H.P., Neupane, N., Kunwar, L.B.,\& Acharya, A. (2015). Birth preparedness and complications readiness among women in Lekhnath Municiaplity, Nepal. Global Journal of Medicine and Public Health,4(3). Retrieved from http://gjmedph .com /uploads/O1Vo4No3.pdf.

Karkee, R., Lee, A. H.,\& Binns, C.W. (2013). Birth preparedness and skilled attendance at birth in Nepal: Implications for achieving millennium development goal 5. Midwifery. Retrieved from www.elsevier.com/midw.

Kaso, M.,\& Addisse, M. (2014). Birth preparedness and complication readiness in Robe Woreda of Central Ethiopia: A cross-sectional study. Reproductive Health. Retrieved from www.reproductive-health-journal.com/content/11/1/55. 
Markos, D.,\& Bogale, D. (2014). Birth preparedness and complication readiness among women of child bearing age group in Gobaworeda, Oromia region, Ethiopia. BMC Pregnancy and Childbirth. Retrieved from http://www.biomedcentral.com/1471-2393/14/282.

Ministry of Health and Population (MoHP), New ERA, and ICF International. (2012). Nepal demographic and health survey 2011. Kathmandu: MoH Population, New ERA, \& ICF International.

Ministry of Health and Population (MoHP), New ERA, and Macro International Inc. (2007). New ERA, and Macro International Inc. Nepal demographic and health survey 2006. Kathmandu: MoH Population, New ERA, \& Macro International Inc.

Tura, D., G., Afework, M. F., \& Yalew, A.W. (2014). Factors affecting birth preparedness and complication readiness in Jimma zone, Southwest Ethiopia: A multilevel analysis. The Pan African Medical Journal. Retrieved from http://www.ncbi.nlm.nih.gov/ pubmed/25870727. 